\title{
Effects of Whole Body Vibration Exercise on the Muscle Strength, Balance and Falling Efficacy of Super-aged Elderly: Randomized Controlled Trial Study
}

\author{
Jin-Hyuk Seo, PT, MS • Myung-Mo Lee, PT, $\mathrm{PhD}^{1 \dagger}$ \\ Department of Physical Therapy, Graduate School of Health and Medicine, Daejeon University \\ ${ }^{1}$ Department of Physical Therapy, Daejeon University
}

Received: November 18, 2019 / Revised: December 9, 2019 / Accepted: January 1, 2020

(C) 2020 J Korean Soc Phys Med

\section{| Abstract |}

PURPOSE: This study examined the effects of a whole body vibration-exercise program on the muscle strength, balance, and falling efficacy of super-aged women.

METHODS: Thirty participants, who are over 75 years of age, were recruited. They were assigned randomly to an experimental group $(\mathrm{n}=15)$, which received whole body vibration exercise, and a control group $(\mathrm{n}=15)$, which received an exercise program that did not include vibration. The interventions lasted for four weeks, three times a day, and 25 minutes per session. To compare the effects of the intervention, a 30-second chair stand test (CST), Korean version of Berg balance scale (K-BBS), functional reach test (FRT), timed up and go test (TUG), and Korean version of the falls efficacy scale (K-FES) was used.

RESULTS: The experimental group showed a significant increase $(\mathrm{p} .<05)$ before and after the intervention in the chair

$\uparrow$ Corresponding Author : Myung-Mo Lee mmlee@dju.kr, https://orcid.org/0000-0002-2192-1701

This is an Open Access article distributed under the terms of the Creative Commons Attribution Non-Commercial License (http://creativecommons.org/licenses/by-nc/3.0) which permits unrestricted non-commercial use, distribution, and reproduction in any medium, provided the original work is properly cited. stand test (CST), Korean version of the Berg balance scale (K-BBS), functional reach test (FRT), timed up-and-go (TUG), and Korean version of the fall efficacy scale (K-FES). Compared to the control group, the experiment group showed a more significant increase $(\mathrm{p} .<05)$ in the CST, K-BBS, and FRT.

CONCLUSION: A whole body vibration exercise program could be suggested as an effective intervention method for muscle and balance strengthening for super-aged women.

Key Words: Aged, Vibration, Muscle strength, Postural balance, Accidental falls

\section{Introduction}

With the increasing average life expectancy and progress in medical technology, the population of the elderly is increasing at a tremendous rate [1]. According to Statistics Korea, the elderly population is $7,685,000$, comprising $14.9 \%$ of the total population. With the gradual increase annually, the elderly are expected to constitute $43.9 \%$ of the total population by 2060 [2]. As the elderly age, chronic diseases, such as diabetes, cardiovascular disease, malignant neoplasm, arthritis, and osteoporosis, will become more 
prevalent and increase the death rate [3]. In addition, the quality of life of the elderly decrease, and new modern social problems arise due to a lack of social policy and awareness of the graying society [4].

Physiological changes caused by ageing decrease the proprioception [5] and cognitive function [6], which decreases muscle strength. The changes result in a weakening of muscle strength and endurance, muscle atrophy, and contraction rate. Sarcopenia becomes greater in people aged 70 years or more and is more conspicuous in elderly people who are less active [7]. Muscle weakness in the elderly decreases the reflex ability upon sudden changes and affects balance.

A decrease in balance ability also affects the gait speed and changes in stride. Balance and gait are essential factors for the successful performance of most activities of daily living, and it has a close relationship with the quality of life [8]. Weakened balance and gait ability increase the vulnerability to falls, leading to secondary complications and an increase in death rate [9]. Falling is a preventable health issue for the elderly. Moreover, the incidence may be reduced by $20 \sim 50 \%$ if the causative factors are found, and appropriate interventions are made [10]. A decrease in the muscle strength of the lower extremities, balance, postural control, and gait ability are important factors that cause falls, and to prevent falling, enhancements of the lower extremity muscle strength, endurance, and balance are crucial [11].

Recently, alternative exercise methods that do not place physical pressure and evenly control gravity by applying vibration to the muscles have been introduced [12]. Whole body vibration exercise is an exercise method that induces muscle contractions through vibration by standing vertically on a plate without any resistance and making various static and dynamic postures [13]. Different amplitudes and frequencies result in a high velocity, leading to a hypergravity status, concentric contraction, and eccentric contractions of the muscles [14].
Whole body vibration was initially used as an intervention to recover the muscle strength of astronauts, but it was later reported to have effects on the muscle strength and endurance of athletes [15]. As various settings and exercise programs of vibration exercises have been reported, many studies have revealed the effects on people with stroke [16], cerebral palsy [17], spinal cord injuries [18], and obese women [19]. Recently, a vibration study was reported to have safe and enhancing effects on balance, gait, and muscle strength of the elderly population [20]. In addition, vibration exercises have effects of increasing bone density, lower extremity muscle strength, and functional mobility [21].

Despite the need for various compositions and intensity of a whole body vibration-exercise program, there is little evidence of the effects on the super aged elderly. Therefore, this study examined the effects of a whole body exercise program on muscle strength, balance, and fall efficacy. In addition, the usability of this program in clinical settings was examined.

\section{Method}

\section{Participants}

This study recruited 64 super aged women who participated in the program provided by $\mathrm{J}$ nursing facility in I city, North Jeolla Province. The inclusion criteria were as follows: (1) over the age of 75 years, (2) could maintain a squat position for 10 seconds while holding a bar, (3) could walk for 15 minutes without any aids, (4) were independent in their activities of daily living (ADL), and (5) had scores over 24 in the Korean version of mini-mental state examination (MMSE-K). The participants were excluded from the study if they had the following: (1) kidney, liver, or cognition problems; (2) an artificial pacemaker; (3) osteopathic issues that could affect the results of the study; and (4) had participated in less than $80 \%$ of the intervention. All the participants were fully 
informed on the contents and purpose of the study, study process, protection of the rights of the participants, and safety issues of participation. All participants participated voluntarily, and 30 participants signed the written consent form. The Ethics Committee of Daejeon University approved this study, which has been registered in the WHO International Clinical Trials Registry Platform: KCT0004376.

\section{Procedures}

This study is a before and after intervention design, and the appropriate number of participants was determined using the G-Power Ver. 3.1 program. Based on the major effect size results of [22], when the effect size (d), significance level, and test power were set to $.94, \alpha=.05$, and $(1-\beta)=.8$, at least 11 participants were required for each group. Therefore, at least 15 participants were recruited, considering a dropout rate of $20 \%$.

All participants were assigned randomly to either an experimental group $(\mathrm{n}=15)$ or control group $(\mathrm{n}=15)$ using a random number production program after making the initial assessments. The experimental group was provided with an exercise program along with whole body vibration, whereas the control group received an exercise program without vibration. All interventions were provided three times a week and 25 minutes per session for four weeks. To compare the effects of the intervention, a 30-second chair stand test (CST), Korean version of Berg balance scale (K-BBS), functional reach test (FRT), timed up and go test (TUG), and Korean version of the falls efficacy scale (K-FES) was used. The participants were blinded to the group they had been assigned to, and the data collected after the intervention were compared and analyzed.

\section{Intervention}

The experimental group performed the exercise on top of the whole body vibration plate to strengthen the lower extremities. This study used the SW-VH11 (Sonic world, Korea) for vibration. This device is $610 \mathrm{~mm} \times 730 \mathrm{~mm} \times$ $1490 \mathrm{~mm}$ in size, and it produces vibration with a mechanism similar to a woofer speaker.

The device is composed of a screen display unit, control unit, power unit, and a handle, where the vibration frequency ranges from four to $30 \mathrm{~Hz}$, sonar intensity from 0 to 99 , and it can be controlled within eight different settings. This study has set the vibration to $30 \mathrm{~Hz}$ [23], and sonar intensity was set to 30 , which was level 4 . The exercise program provided a modified program reported elsewhere [21], and it consisted of weight bearing (ant-post/right-left), tandem standing, calf raise, tiptop raise, semi-Squat $\left(45^{\circ}\right)$, and one leg stand for lower extremity strengthening. Five minutes of stretching were provided for warm up and cool down before and after the intervention, and the exercise was performed for 15 minutes. Each motion was repeated 10 times for 15 seconds. To increase the interest and the sense of accomplishment for the interventions provided each week, the resting time was decreased from the initial 90 seconds and more movements were added for increased intensity (Table 1) (Fig. 1). Considering that the cushion of the shoes can absorb the vibration from the plate, all participants performed the exercises barefoot. The intervention was stopped immediately in cases where the participants reported pain, difficulty in breathing, and dizziness. The pulse rate and blood pressure were considered for determining the rest time and exercise intensity. All interventions were provided three times a week, 25 minutes per session for four weeks. The control group performed the exercise program without the vibration.

\section{Measurement and Procedure}

\section{1) Muscle strength}

A 30-second chair stand test (CST) was used to measure the muscle strength of the participants. The participants 
Table 1. Whole body Vibration Exercise Program

\begin{tabular}{cccccc}
\hline Week & Exercise Position & Frequency (Hz) & Duration (min) & Rest Time (sec) & Repetitions \\
\hline 1 & (1)(2)(3)(4) & 30 & 15 & 90 & 10 \\
2 & (1)(2)(3)(4)(5) & 30 & 15 & 60 & 10 \\
3 & (1) (2)(3)(4)(5)(6) & 30 & 15 & 30 & 10 \\
4 & (1)(2) (3)(4)(5)(6) & 30 & 15 & 20 & 10 \\
\hline
\end{tabular}

(1)Weight bearing(ant-post/right-left); (2)Tandem standing; (3)Calf raise; (4)Tiptop raise; (5)Semi-squat(45); (6)One leg stand

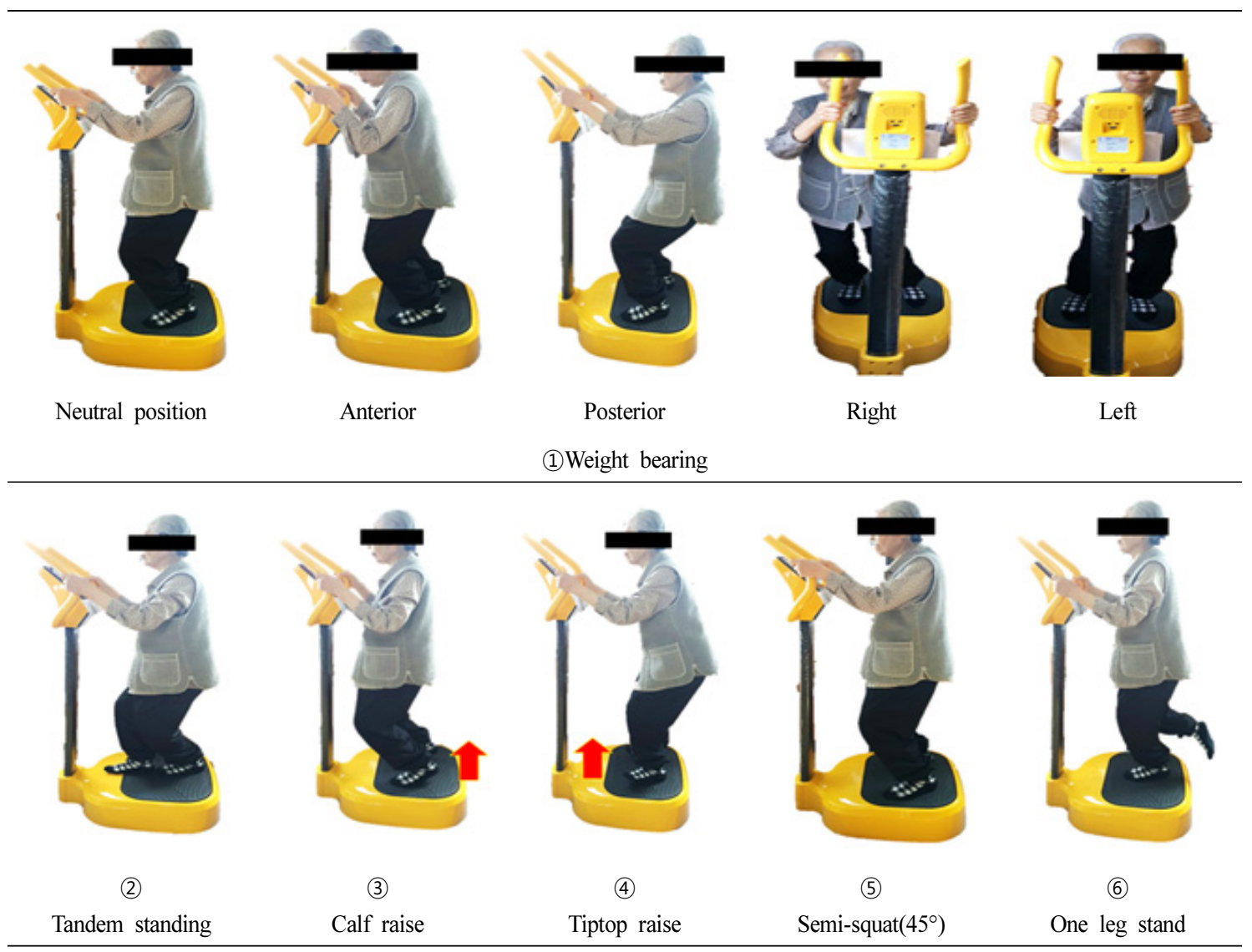

Fig. 1. Whole body vibration exercise program.

sat on a chair without handlebars and back support with both arms crossed on top of the chest. The number of repetitions in the 30 seconds, where the participants fully extended their knees and returned to a standing position followed by sitting back, was recorded. This was measured three times to derive a mean value [24].

\section{2) Dynamic balance}

The Korean version of Berg balance scale (K-BBS) was used to measure the balance ability. This assessment 
included 14 items that measure the static and dynamic balance, and it had a total score of 56, in which each item score ranged from zero to four. A higher score means better balance, and BBS has high intra-rater reliability $(r=.98)$ and interrater reliability $(\mathrm{r}=.97)$ [25].

A functional reach test (FRT) was used to screen the balance and the risk of falling [26]. The participants maintained their balance in the standing position to reach the arms to the maximum length. The distance of the arms was measured, and it has a high interrater and intra-rater reliability of $\mathrm{r}=.98$ and $\mathrm{r}=.92$, respectively [27]. In addition, TUG was used to measure the functional mobility. The participant started from a seated position on a chair, and with the start cue, they stood up to walk around the target three meters away to return to the starting position. The time it took to return to the starting position was measured. This assessment had an intra-rater and interrater reliability of $\mathrm{r}=.99$ and $\mathrm{r}=.98$, respectively [28].

\section{3) Falls Efficacy}

The Korean version falls efficacy scale (K-FES) was used to determine the anxiety and fear towards falling [29]. This assessment showed the level of fear from 10 different actions needed in the activities of daily living with scores ranging from one to 10 . If the participants felt a fear of falling, the score was one, whereas 10 was given if they felt confident. The total score ranged from 10 to 100 , where a lower score means more fear towards falling. The item internal consistency had a Cronbach's $\sigma$ of .75 [30].

\section{Statistical analysis}

The collected data was analyzed using SPSS version 25.0 (IBM, Chicago, IL, USA). The general characteristics of the participants were found through descriptive statistics to yield the mean and standard deviation values. Normality was found through a Shapiro-Wilk test. The general characteristics and the test of homogeneity of the pre-intervention values for each group were found through a $\chi 2$ test and an independent t-test. The homogeneity of the dependent variables of each group was found through an independent $t$-test. To compare the intervention results between the groups, an independent t-test and $\chi 2$ test were used, and a paired t-test was used to compare the dependent variables within the groups. The statistically significant level was set to $a=.05$.

\section{Result}

Data of 15 participants from the experimental group and 15 participants from the control group were collected for analysis. The general characteristics and all dependent variables before the intervention were homogeneous (Table $2,3)$. Both groups showed statistically significant increases $(p<.05)$ in the CST, K-BBS, TUG, and K-FES before and after the intervention, but only the experimental group showed a significant increase $(p<.05)$ in the FRT. The

Table 2. General Characteristics

\begin{tabular}{ccccc}
\hline & Experimental Group $(\mathrm{n}=15)$ & Control Group $(\mathrm{n}=15)$ & $\mathrm{t} / \chi^{2}$ & $\mathrm{p}$ \\
\hline Age(year) & $83.13 \pm 3.78^{\mathrm{a}}$ & $84.00 \pm 3.66$ & -.638 & .529 \\
Height $(\mathrm{cm})$ & $146.37 \pm 5.75$ & $148.60 \pm 4.98$ & -1.137 & .265 \\
Weight $(\mathrm{kg})$ & $55.77 \pm 10.88$ & $58.50 \pm 9.06$ & -.747 & .461 \\
BMI $\left(\mathrm{kg} / \mathrm{m}^{2}\right)$ & $25.90 \pm 4.33$ & $26.49 \pm 3.84$ & -.395 & .696 \\
MMSE-K(score) & $25.00 \pm 1.41$ & $25.40 \pm 1.77$ & -.685 & .499 \\
\hline
\end{tabular}

${ }^{\mathrm{a}} \mathrm{Mean} \pm$ Standard deviation,

BMI=body mass index; MMSE-K=Korean version of mini-mental state examination 
Table 3. Comparisons of the Dependent Variables before and after the Intervention between the Groups.

\begin{tabular}{|c|c|c|c|c|}
\hline & & Experimental Group $(n=15)$ & Control Group $(\mathrm{n}=15)$ & $\mathrm{t}(\mathrm{p})$ \\
\hline \multirow{4}{*}{$\begin{array}{l}\text { CST } \\
\text { (count) }\end{array}$} & Pre & $6.83 \pm 1.53^{\mathrm{a}}$ & $7.28 \pm 2.02$ & $-.689(.497)$ \\
\hline & Post & $9.72 \pm 1.37$ & $8.66 \pm 2.08$ & \\
\hline & Post-pre & $2.89 \pm 1.08$ & $1.38 \pm 1.15$ & $-3.969(.001)$ \\
\hline & $\mathrm{t}(\mathrm{p})$ & $10.331(.000)$ & 4.633(.000) & \\
\hline \multirow{4}{*}{$\begin{array}{l}\text { K-BBS } \\
\text { (score) }\end{array}$} & Pre & $39.50 \pm 4.56$ & $41.50 \pm 5.12$ & $-1.129(.268)$ \\
\hline & Post & $47.28 \pm 2.40$ & $44.35 \pm 5.72$ & \\
\hline & Post-pre & $7.78 \pm 3.88$ & $2.85 \pm 2.90$ & $-4.157(.001)$ \\
\hline & $\mathrm{t}(\mathrm{p})$ & 7.773(.000) & $3.811(.002)$ & \\
\hline \multirow{4}{*}{$\begin{array}{l}\text { FRT } \\
\text { (score) }\end{array}$} & Pre & $15.03 \pm 3.17$ & $16.02 \pm 4.19$ & $-.730(.471)$ \\
\hline & Post & $18.78 \pm 2.96$ & $17.33 \pm 3.54$ & \\
\hline & Post-pre & $3.75 \pm 1.63$ & $1.31 \pm 2.59$ & $-3.129(.007)$ \\
\hline & $\mathrm{t}(\mathrm{p})$ & $8.928(.000)$ & $1.958(.070)$ & \\
\hline \multirow{4}{*}{$\begin{array}{c}\text { TUG } \\
\text { (second) }\end{array}$} & Pre & $16.82 \pm 3.47$ & $15.62 \pm 4.67$ & $.799(.431)$ \\
\hline & Post & $13.45 \pm 1.46$ & $14.01 \pm 3.17$ & \\
\hline & Post-pre & $-3.37 \pm 2.91$ & $-1.61 \pm 2.03$ & $1.669(.117)$ \\
\hline & $\mathrm{t}(\mathrm{p})$ & $-4.482(.001)$ & $-3.081(.008)$ & \\
\hline \multirow{4}{*}{$\begin{array}{l}\text { K-FES } \\
\text { (score) }\end{array}$} & Pre & $74.28 \pm 17.18$ & $74.50 \pm 14.02$ & $-.038(.970)$ \\
\hline & Post & $86.14 \pm 16.37$ & $83.35 \pm 15.03$ & \\
\hline & Post-pre & $11.86 \pm 9.98$ & $8.85 \pm 8.19$ & $-.819(.426)$ \\
\hline & $t(p)$ & $4.604(.000)$ & $4.185(.001)$ & \\
\hline
\end{tabular}

${ }^{\mathrm{a}}$ Mean \pm Standard deviation,

CST=30-second chair stand test; K-BBS=Korean version of the Berg balance scale; FRT=functional reach test; TUG=timed up and go test; K-FES=Korean version falls efficacy scale

experimental group showed a more significant increase in the CST, K-BBS, and FRT than the control group $(\mathrm{p}<.05)$ (Table 3).

\section{Discussion}

This study examined the effects of a whole body vibratio n-exercise program on the muscle strength, balance, and falling efficacy of super-aged women. The experimental group who received whole body vibration exercise showed significant increases $(\mathrm{p}<.05)$ in all items before and after the intervention, and there were more significant differences $(\mathrm{p}<.05)$ in the CST, K-BBS, and FRT than the control group.

In the case of maintaining various static and dynamic postures on top of the vibration plate, the mechanical stimulus from the vibration induces short and quick changes in the muscle-tendon complex, which is referred to as the tonic vibration reflex (TVR). Whole body vibration exercise is a method that stimulates the muscles through spinal reflexes by vibration stimuli with the mechanism of tonicity [31].

A whole body vibration stimulus was reported to not only increase the muscle strength of athletes [32], but also 
had positive effects of increasing the muscle strength and physical function of people with osteoporosis [33], Parkinson's disease [34], stroke [16], and spinal cord injuries [18]. The effects of whole body vibration depend on the frequency, amplitude, and intensity, where the vibrational frequency is the most important factor. A previous study [35] suggested that the frequency should be between 20 and $50 \mathrm{~Hz}$ because a frequency below $20 \mathrm{~Hz}$ results in excessive relaxation of the muscles, and a frequency greater than $50 \mathrm{~Hz}$ may result in muscle pain. Many studies showed that $30 \mathrm{~Hz}$ is safe to use, and muscle activation is at the optimal state [23]. Therefore, this study also used $30 \mathrm{~Hz}$ on the participants.

CST was used as a measurement to examine the effects of whole body vibration exercise on the lower extremity muscle strength. The results revealed a statistically significant increase $(\mathrm{p}<.05$, effect size $\mathrm{d}=1.99)$ from 6.83 before the intervention to 9.72 after the intervention for the experimental group, and 7.28 before the intervention to 8.66 after the intervention for the control group ( $\mathrm{p}<.05$, effect size $\mathrm{d}=.67$ ) This concurs with a previous study [36] that reported a significant increase in the CST after the provision of whole body vibration exercise to the elderly group. The result of this study also supports previous findings [37], which reported that vibration exercise increases the lower extremity muscle strength. Whole body vibration stimulates the muscle spindle and activates the proprioceptors and Golgi's tendon organs. This reaction leads to a reflexive contraction of the muscle and results in a positive increase in muscle activation when the vibration is given. Despite the intervention provided to super aged women, the muscles around the knee joint was stimulated continuously by making the squat position in every exercise movements [38], and the intervention time was longer than the method reported elsewhere [21]. Owing to the intervention provided for a longer time, the experimental group may have shown a greater increase.

The K-BBS, FRT, and TUG were used to assess the dynamic balance. As a result, after four weeks of exercise, the K-BBS score of the experimental group increased significantly from 39.50 before the intervention to 47.28 after the intervention $(\mathrm{p}<.05$, effect size $\mathrm{d}=2.13)$, and the control group also showed a significant increase $(\mathrm{p}<.05$, effect size $\mathrm{d}=.53$ ) from 41.50 before the intervention to 44.35. A comparison before and after the intervention between the groups revealed the experimental group to have a more significant difference $(\mathrm{p}<.05)$, suggesting that whole body vibration exercise is effective in improving balance. The results of this study support the results of a previous study [39], which demonstrated that balance was improved with physical therapy and vibration exercise for six weeks in 22 out of 42 elderly subjects aged between 63 to 98 , and another study [20], which proved that there is a significant increase in the scores from 37.93 before the intervention to 48.50 after the exercise for eight weeks, three times a week in 38 out of 77 elderly people over the age of $80(p<.05$, effect size $d=7.85)$. In another result from FRT to assess the dynamic balance, the experimental group showed a significant increase from $15.03 \mathrm{~cm}$ before the intervention to $18.78 \mathrm{~cm}$ after the exercise $(\mathrm{p}<.05$, effect size $\mathrm{d}=1.22$ ), and the control group showed an increase from $16.02 \mathrm{~cm}$ before the intervention to $17.33 \mathrm{~cm}$ after the exercise. On the other hand, the control group showed no significant change ( $\mathrm{p}>.05$, effect size $\mathrm{d}=.38$ ). A comparison of the groups showed that the experimental group exhibited more changes before and after the intervention than the control group $(\mathrm{p}<.05)$.

A previous study [21] reported that the experimental group of elderly patients with a mean age of 77.5 ( $\mathrm{p}<.05$, effect size $d=-.70$ ) showed a significant decrease in TUG from 15.3 seconds before the intervention to 12 seconds after the exercise for six weeks, whereas the control group showed no significant difference in the TUG, which changed from 14.8 seconds to 14.3 seconds ( $p>05$, effect size $\mathrm{d}=-.07$ ). The gait was improved significantly (by $10.1 \%$ ) after administering whole body vibration to elderly 
women [36]. The present study also showed a significant decrease in the TUG from 16.82 seconds before the intervention to 13.45 seconds after the exercise in the experimental group, and 15.62 seconds to 14.01 seconds in the control group, but the difference was not significant. This may be due to the small change in the measured variables considering that the participants were super aged elderly.

Many studies have examined the effects of whole body vibration exercise on the fall efficacy. One study [40] reported that 94 elders showed significant improvements in postural control and falling frequency after providing whole body vibration exercise for one year, three times a week. In addition, another study [20] showed that 77 elders over the age of 80 and who had experienced falls showed a significant increase in both the whole body vibration group $(n=38)$ and control group $(n=39)$ after providing the intervention for eight weeks, three sessions per week, and 60 minutes per session. On the other hand, the study also showed no significant difference regarding the change between the groups. The falls efficacy in this study showed statistically significant increase in both groups. The experimental group showed a statistically significant increase from 74.28 before the intervention to 86.14 after the intervention ( $p<.05$, effect size $d=.71)$, and the control group showed an increase from 74.50 to 83.35 in $(p<.05$, effect size $d=.61)$. No significant difference in the amount of change was observed between the groups. Although this study analyzed the data from super aged elders over the age of 75 years, the participants were all independent regarding the ADL performance. Therefore, expectations for a statistical amount of change in the falls efficacy before and after the intervention may be difficult.

Lower extremity strengthening via whole body vibration may increase the balance and mobility and decrease fear of falling. Strong vibration and squatting position in the entire exercise program suggests that this is a difficult intervention method to administer, but this program can be applied to people with all abilities depending on the composition of the program.

Despite these results, this study had some limitations. First, the intervention period was relatively short, lasting for only four weeks. This length did not allow sufficient time for follow up investigations to determine the transfer of the exercise effects. Second, the 30 participants were super aged women, making it difficult to generalize the intervention to the entire elderly population. Third, this study investigated healthy women over the age of 75 ; hence, the results should not be generalized to the entire elderly population. Fourth, personal lifestyle, nutritional status, and environmental factors were not considered. Various studies in the future need to modify the limitations of this study to prove that whole body vibration exercise is effective in increasing the muscle strength, balance, and falling efficacy of super aged elderly subjects.

\section{Conclusion}

This study examined the effects of a whole body vibration-exercise program on the muscle strength, balance, and falling efficacy of super-aged women. The experimental group who performed the whole body vibration-exercise program showed significant improvements in the CST, K-BBS, TUG, and K-FES compared to the control group who performed sham therapy. When considering these results, the whole body vibration-exercise program could be suggested as an effective intervention method for muscle and balance strengthening for super-aged women.

\section{References}

[1] Kannus P, Sievänen H, Palvanen M, et al. Prevention of falls and consequent injuries in elderly people. The Lancet. 2005;366(9500):1885-93.

[2] office Kns: Korea national statistical office., 2019. 
Available at: http://kostat.go.kr/portal/korea/kor_nw/1/ 6/1/index.board?bmode=read\&aSeq=377701.

[3] Ciolac EG. Exercise training as a preventive tool for age-related disorders: a brief review. Clinics. 2013;68(5): 710-7.

[4] Kim KL. Effects of Combined Exercise Training on Body Composition, Balance and Arterial Compliance in Elderly People. The Korean Society of Living Environmental System. 2011;18(2):255-63.

[5] Hess JA, Woollacott M. Effect of high-intensity strength-training on functional measures of balance ability in balance-impaired older adults. J Manipulative Physiol Ther. 2005;28(8):582-90.

[6] Kollegger H, Baumgartner C, Wöber C, et al. Spontaneous body sway as a function of sex, age, and vision: posturographic study in 30 healthy adults. Eur Neurol. 1992;32(5):253-9.

[7] Kwak Y-S, Um S-Y, Son T-G, et al. Effect of regular exercise on senile dementia patients. Int J Sports Med. 2008;29(06):471-4.

[8] Rogers ME, Rogers NL, Takeshima N, et al. Methods to assess and improve the physical parameters associated with fall risk in older adults. Prev Med. 2003;36(3):255-64.

[9] Miller CA. The connection between drugs and falls in elders. Geriatric Nursing. 2002;2(23):109-10.

[10] Gillespie LD, Gillespie WJ, Robertson MC, et al. Interventions for preventing falls in elderly people. Cochrane database of systematic reviews. 2003(4).

[11] Runge M, Rehfeld G, Resnicek E. Balance training and exercise in geriatric patients. J Musculoskelet Neuronal Interact. 2000;1(1):61-5.

[12] Delecluse C, Roelants M, Verschueren S. Strength increase after whole-body vibration compared with resistance training. Med Sci Sports Exerc. 2003;35(6):1033-41.

[13] Roelants M, Delecluse C, Verschueren SM. Wholebodyvibration training increases knee-extension strength and speed of movement in older women. J Am Geriatr Soc. 2004;52(6):901-8.
[14] Cardinale M, Wakeling J. Whole body vibration exercise: are vibrations good for you? Br J Sports Med. 2005; 39(9):585-9.

[15] Kim Y. The effects of whole body vibration on the improvement of lower extremity function and isokinetic musular strength on Korean male volley ball players. Doctor's Degree. Yongin University. 2015.

[16] In T-S, Song C-H. The effects of whole body vibration on knee extensor strength, and balance and walking ability with chronic stroke. Journal of the Korean Society of Physical Medicine. 2010;5(4):675-83.

[17] Jung Y. The effects of whole body vibration combined with action observation on gross motor function, balance and gait in children spastic with cerebral palsy. Master's Degree. Sahmyook University. 2017.

[18] Ahn MC, Song CH. Immediate effects of local vibration on ankle plantarflexion spasticity and clonus of both the gastrocnemius and soleus in patients with spinal cord injury. Journal of the korean society of physical medicine. 2016;11(2):1-11.

[19] Ryu B. A study on effects of walking exercise applying vibration movement on a body structure in the middle-aged obese female. Master's Degree. Yongin University. 2007.

[20] Pollock RD, Martin FC, Newham DJ. Whole-body vibration in addition to strength and balance exercise for falls-related functional mobility of frail older adults: a single-blind randomized controlled trial. Clin Rehabil. 2012;26(10):915-23.

[21] Bautmans I, Van Hees E, Lemper J-C, et al. The feasibility of whole body vibration in institutionalised elderly persons and its influence on muscle performance, balance and mobility: a randomised controlled trial [ISRCTN62535013]. BMC Geriatr. 2005;5(1):17.

[22] Kim Y-M, Park JH. The Effect of Whole-Body Vibration Exercise on Balance, Muscle Strength and Falls Efficacy in the Elderly. Journal of the korean society of physical medicine. 2017;12(4):61-71.

[23] Ritzmann R, Gollhofer A, Kramer A. The influence of 
vibration type, frequency, body position and additional load on the neuromuscular activity during whole body vibration. Eur J Appl Physiol. 2013;113(1):1-11.

[24] Bohannon RW. Sit-to-stand test for measuring performance of lower extremity muscles. Percept Mot Skills. 1995;80(1):163-6.

[25] Berg K, Wood-Dauphine S, Williams J, et al. Measuring balance in the elderly: preliminary development of an instrument. Physiother Can. 1989;41(6):304-11.

[26] Duncan PW, Weiner DK, Chandler J, et al. Functional reach: a new clinical measure of balance. J Gerontol. 1990;45(6):M192-M7.

[27] Kang H-K, Kim Y, Chung Y, et al. Effects of treadmill training with optic flow on balance and gait in individuals following stroke: randomized controlled trials. Clin Rehabil. 2012;26(3):246-55.

[28] Podsiadlo D, Richardson S. The timed "Up \& Go": a test of basic functional mobility for frail elderly persons. J Am Geriatr Soc. 1991;39(2):142-8.

[29] Jang SN, Cho SI, Ou SW, et al. The Validity and Reliability of Korean Fall Efficacy Scale(FES) and Activities-specific Balance Confidence Scale(ABC). Journal of the Korean Geriatrics Society. 2003;7(4):255-68.

[30] Huang HC, Gau ML, Lin WC, et al. Assessing risk of falling in older adults. Public Health Nurs. 2003;20(5): 399-411.

[31] Cochrane DJ. The potential neural mechanisms of acute indirect vibration. J Sports Sci Med. 2011;10(1):19.

[32] Cochrane DJ, Legg SJ, Hooker MJ. The short-term effect of whole-body vibration training on vertical jump, sprint, and agility performance. The Journal of Strength \& Conditioning Research. 2004;18(4):828-32.
[33] Rubin C, Turner AS, Bain S, et al. Anabolism: Low mechanical signals strengthen long bones. Nature. 2001;412(6847):603.

[34] Turbanski S, Haas CT, Schmidtbleicher D, et al. Effects of random whole-body vibration on postural control in Parkinson's disease. Res Sports Med. 2005;13(3):243-56.

[35] Rittweger J. Vibration as an exercise modality: how it may work, and what its potential might be. Eur J Appl Physiol. 2010;108(5):877-904.

[36] Furness TP, Maschette WE. Influence of whole body vibration platform frequency on neuromuscular performance of community-dwelling older adults. The Journal of Strength \& Conditioning Research. 2009; 23(5):1508-13.

[37] Verschueren SM, Roelants M, Delecluse C, et al. Effect of 6 month whole body vibration training on hip density, muscle strength, and postural control in postmenopausal women: a randomized controlled pilot study. J Bone Miner Res. 2004;19(3):352-9.

[38] Roelants M, Verschueren SM, Delecluse C, et al. Whole-body-vibration-induced increase in leg muscle activity during different squat exercises. J Strength Cond Res. 2006;20(1):124.

[39] Bruyere O, Wuidart M-A, Di Palma E, et al. Controlled whole body vibration to decrease fall risk and improve health-related quality of life of nursing home residents. Arch Phys Med Rehabil. 2005;86(2):303-7.

[40] Bogaerts A, Verschueren S, Delecluse C, et al. Effects of whole body vibration training on postural control in older individuals: a 1 year randomized controlled trial. Gait Posture. 2007;26(2):309-16. 